\title{
Informasi Titik-Titik Likuifaksi akibat Gempa Bumi di Kota Padang
}

\author{
Liliwarti \\ Teknik Sipil Politeknik Negeri Padang \\ liliwartie@gmail.com
}

\begin{abstract}
Abstrak-Padang Sumatera Barat merupakan daerah rawan gempa, gempa bumi dapat menimbulkan bahaya likuifaksi yang dapat merusak bangunan dan sarana infrastruktur . Likuifaksi biasanya terjadi pada tanah pasir yang jenuh air, saat terjadi gempa tegangan geser tanah menurun sehingga tanah tidak mampu menahan beban yang diatas dan mengakibatkan bangunan amblas. Dalam makalah ini disajikan tingkat potensi likuifaksi berdasarkan data sondir (Cone Penetration Test) di kota Padang. Titik lokasi penyelidikan terdiri dari 9 titik lokasi yang tersebar di kota Padang. Hasil analisa menunjukkan bahwa pada titik penyelidikan dengan lokasi GOR Haji Agussalim pada kedalaman 5 - 6 meter berpotensi likuifaksi dengan nilai indek likuifaksi $>5$. Koto tangah pada kedalaman $3.8 \mathrm{~m}-4.4 \mathrm{~m}$ berpotensi likuifaksi nilai indek likuifaksi 12.69, dan Sungai sapih berpotensi likuifaksi pada kedalaman $4.8 \mathrm{~m}$ dengan nilai indek likuifaksi 5.2. Hos Cokroaminoto, Purus serta Siteba mempunyai potensi yang sangat kecil untuk terjadi likuifaksi. Sedangkan Ujung Gurun, berpotensi likuifaksi pada kedalaman $3.5 m-6 m$, Lolong berpotensi likuifaksi pada kedalaman $1.4 \mathrm{~m}-2 \mathrm{~m}$, Chatib Sulaiman berpotensi likuifaksi pada kedalaman $1.2 \mathrm{~m}-4.8 \mathrm{~m}$.
\end{abstract}

Kata kunci: CPT, likuifaksi, kuat geser

\section{PENDAHULUAN}

Gempa bumi Padang 30 September 2009 dengan kekuatan 7,6 pada skala Richter menyebabkan terjadi kerusakan bangunan dan infrastruktur yang cukup parah, banyak bangunan yang amblas, fenomena amblasnya bangunan tersebut banyak pakar geoteknik berpendapat bahwa peristiwa tersebut terjadinya likuifaksi akibat gempa bumi.

Likuifaksi (liquefactiont) adalah peristiwa hilangnya kekuatan lapisan tanah akibat adanya gempa bumi. Likuifaksi terjadi biasanya pada tanah yang jenuh air, tekanan air pori menjadi meningkat dan tanah tidak mempunyai daya dukung, sehingga tidak mampu menahan beban yang ada di atasnya, menyebabkan amblasnya bangunan ke dalam tanah (M.Das, 1992).

Informasi mengenai kerentanan wilayah terhadap potensi likuifaksi sangat penting dilakukan dalam rangka melakukan usaha mitigasi, untuk meminimalkan akibat yang ditimbulkan oleh gempa bumi. Pada makalah ini disajikan informasi lokasi /titik yang berpotensi likuifaksi berdasarkan data lapangan yaitu sondir (CPT).
Untuk pembangunan kota Padang kedepannya perlu adanya informasi/peta terhadap kerentanan tanah terhadap potensi likuifaksi, hal ini sangat mendesak untuk dilaksanakan mengingat Padang adalah rawan bencana

\subsection{Likuifaksi (liquefactiont)}

Likuifaksi (liquefactiont) adalah peristiwa hilangnya kekuatan lapisan tanah akibat adanya getaran, seperti getaran yang disebabkan oleh gempa bumi, sehingga tanah tidak mampu menopang beban yang ada di atasnya. Likuifaksi terjadi biasanya pada tanah yang jenuh air, dimana seluruh rongga rongga dari tanah tersebut dipenuhi air. Pada saat terjadi getaran, maka air memberikan suatu tekanan ke partikel partikel tanah sehingga mempengaruhi kepadatan tanah, tekanan air pori menjadi meningkat dan tanah tidak mempunyai daya dukung, sehingga tidak mampu menahan beban yang ada di atasnya, maka terjadi amblasnya bangunan ke dalam tanah (M.Das, 1992).

Likuifaksi umumnya terjadi pada tanah bergradasi buruk seperti SP (Sandy Poor) atau yang disebut dengan pasir lepas, karena 
tanah ini lebih banyak menyimpan air dari pada tanah bergradasi baik.

\subsection{Penggunaan Uji Lapangan Untuk Evaluasi Potensi Liquefaction}

1.2.1 Evaluasi Potensi liquefaction dengan Uji Sondir

Uji sondir mengukur perlawanan ujung konus $\left(q_{c}\right)$ dan gesekan selimut $\left(f_{s}\right)$ sesuai dengan prosedur ASTM D1586.

\section{a. Metoda Zhou (1981)}

Zhou mengembangkan metode untuk mengevaluasi potensi liquefaction pada tanah pasir dengan uji sondir berdasarkan data lapangan. Berdasarkan cara statistic, disarankan suatu besaran perlawanan ujung sondir kritis sebesar:

$q_{c r .}=q_{\mathrm{sa}}\left[1-0.065\left(W_{\text {w..t. }}\{)\right]\left[1-0.05\left(H_{o}-2\right)\right]\right.$

dimana;

$\mathrm{q}_{\mathrm{cr}}=$ harga perlawanan kritis ujung sondir batas dimana tanah akan mengalami pencairan saat gempa.

$\mathrm{q}_{\mathrm{so}}=$ harga perlawanan kritis ujung sondir yang besaran gempa pada kedalaman muka air tanah $\mathrm{H}_{\mathrm{w}}=2 \mathrm{~m}$ dan tekanan tanah pada ketebalan $\mathrm{H}_{\mathrm{o}}=2 \mathrm{~m}$. Harga $\mathrm{q}_{\mathrm{so}}$ tergantung dari intensitas gempa.

\section{b. Methoda Shibata dan Terapaksa}

$(1987,1988)$

Shibata dan Terapaksa $(1987,1988)$ mengusulkan metoda evaluasi potensi liquefaction berdarkan data sondir.

Prosedur analisis mengikuti cara berikut,

1. Tentukan harga perlawanan ujung sondir yang telah dikoreksi terhadap tegangan efektif $1 \mathrm{~kg} / \mathrm{cm}^{2}$ sebagai berikut:

$$
q_{c 1}=C_{1} \cdot q_{c}=\frac{1.7}{\sigma_{o}+0.7} \cdot q_{c}\left(\mathrm{~kg} / \mathrm{cm}^{2}\right)
$$

dengan $\mathrm{C}_{1}$ adalah fungsi dari $\sigma_{\circ}$ dalam satuan $\mathrm{kg} / \mathrm{cm}^{2}$ pada titik kedalaman ujung sondir.

2. Rasio tegangan siklik yang terjadi di lapangan diperkirakan dengan formula dari Tokimatsu dan Yoshimi (1983) sebagai berikut,

$$
\frac{\tau}{\sigma_{0}^{\prime}}=0.1(M-1) \frac{a_{\max }}{g} \frac{\sigma_{0}}{\sigma_{0}^{\prime}}(1-0.015 z)
$$

$$
\begin{aligned}
& \text { dengan : } \\
& M_{a_{\max }}: \text { besaran gempa, } \\
& \text { бо dan } \sigma 0^{\prime} \quad \text { : tegangan total, } \\
& \mathrm{z} \quad \text { : kedalaman }(\mathrm{m})
\end{aligned}
$$

3. Batas kritis yang memisahkan kejadian liquefaction dan yang tidak dinyatakan dalam nilai perlawanan konus yang dinormalisasi, rasio tegangan siklik dan ukuran butir rata rata partikel tanah yang diberikan oleh persamaan:

$$
\begin{gathered}
\left(q_{c 1}\right)=C_{2}\left[50+200\left(\frac{\left(\tau / \sigma_{0}\right)-0.1}{\left(\tau / \sigma_{0}\right)+0.1}\right] . .(4)\right. \\
\left(\frac{\tau}{\sigma_{0}{ }^{\prime}}\right)=0.1+0.2\left[\frac{\left.\left(q_{c 1} / C_{2}\right)-50\right)}{250-\left(q_{c 1} / C_{2}\right)}\right]
\end{gathered}
$$

..(5)

dimana $\mathrm{C}_{2}=1$ untuk pasir bersih dengan harga $D_{50} \geq 0.25 \mathrm{~mm}$ dan

$$
C_{2}=\frac{D_{50}(\mathrm{~mm})}{0.25(\mathrm{~mm})}
$$

\section{METODE PENELITIAN}

\subsection{Data Umum}

Data penyelidikan lapangan terdiri dari data sondir (CPT), terdiri dari 9 (sembilan) lokasi yang tersebar di kota Padang. Data yang digunakan adalah data sekunder (CPT) pada pembangunan proyek di kota Padang.

\subsection{Analisa Likuifaksi}

Analisa likuifaksi kita menggunakan asumsi kekuatan gempa yaitu $8 \mathrm{SR}$, karena berdasarkan kejadian masa lampau telah terjadi gempa besar 7.9 SR tahun 2009. 
Dari analisis ini akan di dapatkan hasil,

a. Bentuk lapisan tanah berdasarkan kepadatan

b. Penurunan yang terjadi akibat peristiwa liquefaction

c. Nilai CRR dan CSR berdasarkan metoda Yoshimi dan Tokimatsu, dan metoda Shibata dan Terapaksa.

d. Faktor keamanan terhadap bahaya liquefaction

2.3 Menentukan indek Potensi likuifaksi

Untuk menentukan tingkat potensi likuifaksi, dapat dikategorikan berdasarkan indek potensi likuifasi (Liquefaction Potential Index)

Liquefaction Potential Index $(L P I)<5$ : tidak berpotensi likuifaksi

LPI : 5-15 berpotensi likuifaksi

LPI : > 15 sangat berpotensi likuifaksi

\section{HASIL DAN PEMBAHASAN}

Dalam menganalisa potensi likuifaksi dipakai asumsi sebagai berikut:

Asumsi Magnitude Gempa $=8.00$

Asumsi percepatan gempa dibatuan dasar $=$ $0.4 \mathrm{~g}$

\subsection{Hasil Analisa}

a. GOR Haji Agus Salim Padang

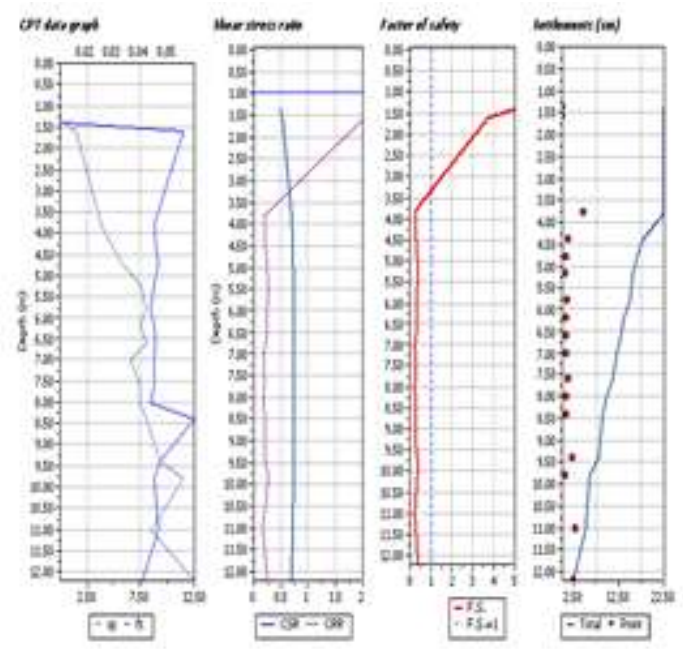

Gambar 4.2. Nilai faktor keamanan dan penurunan

Tabel 4.2.Penurunan dan faktor keamanan

\begin{tabular}{c|c|l|l}
\hline $\begin{array}{l}\text { No } \\
\text { Titik }\end{array}$ & $\begin{array}{l}\text { Kedalaman } \\
(\mathrm{m})\end{array}$ & $\begin{array}{l}\text { Penur } \\
\text { Nan }(\mathrm{cm})\end{array}$ & SF \\
\hline 3 & 3,8 & 4,77 & 0.29 \\
4 & 4,4 & 1,28 & 0.29 \\
5 & 4,8 & 0,82 & 0.32 \\
6 & 5,2 & 0,78 & 0.36 \\
7 & 5,8 & 1,18 & 0.35 \\
8 & 6,2 & 0,82 & 0.31 \\
9 & 6,6 & 0,81 & 0.32 \\
10 & 7,0 & 0,91 & 0.25 \\
11 & 7,6 & 1,32 & 0.27 \\
12 & 8,0 & 0,90 & 0.25 \\
13 & 8,4 & 0,85 & 0.29 \\
14 & 9,4 & 2,13 & 0.29 \\
15 & 9,8 & 0,77 & 0.37 \\
16 & 11,0 & 2,82 & 0.24 \\
17 & 12,2 & 2,36 & 0.37 \\
\hline \multicolumn{3}{|c}{ Total penurunan =22,5 cm } \\
\hline
\end{tabular}

Lokasi yang berpotensi likuifaksi yaitu pada kedalaman 3,8 m sampai $12,2 \mathrm{~m}$ yang ditandai dengan nilai faktor keamanan $<1$. Total penurunan yang terjadi yaitu sebesar $22,5 \mathrm{~cm}$.

\section{b. Lokasi Hos Cokroaminoto Padang}

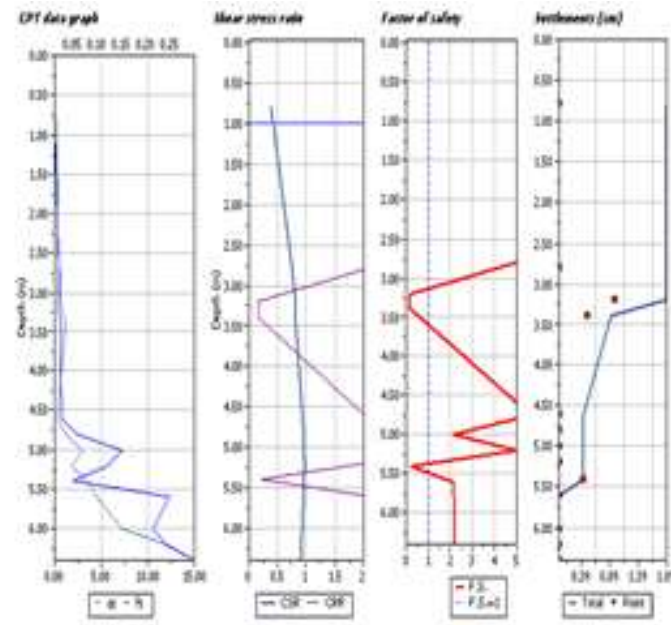

Gambar 4.3. Nilai faktor keamanan dan penurunan

Tabel 4.3.Penurunan dan faktor keamanan

\begin{tabular}{l|c|c|l}
\hline $\begin{array}{l}\text { No } \\
\text { Titik }\end{array}$ & $\begin{array}{c}\text { Kedalaman } \\
(\mathrm{m})\end{array}$ & $\begin{array}{c}\text { Penurunan } \\
(\mathrm{cm})\end{array}$ & SF \\
\hline 3 & 3,2 & 0,98 & 0.20 \\
4 & 3,4 & 0,49 & 0.19 \\
9 & 5,4 & 0,42 & 0.22 \\
\hline \multicolumn{4}{r}{ Total penurunan $=1,89 \mathrm{~cm}$}
\end{tabular}


Potensi likuifaksi terdapat pada kedalaman $3,2 \mathrm{~m}, 3,4 \mathrm{~m}$ dan $5,4 \mathrm{~m}$. Total penurunan yang terjadi yaitu sebesar $1,89 \mathrm{~cm}$.

\section{c. Purus Padang}
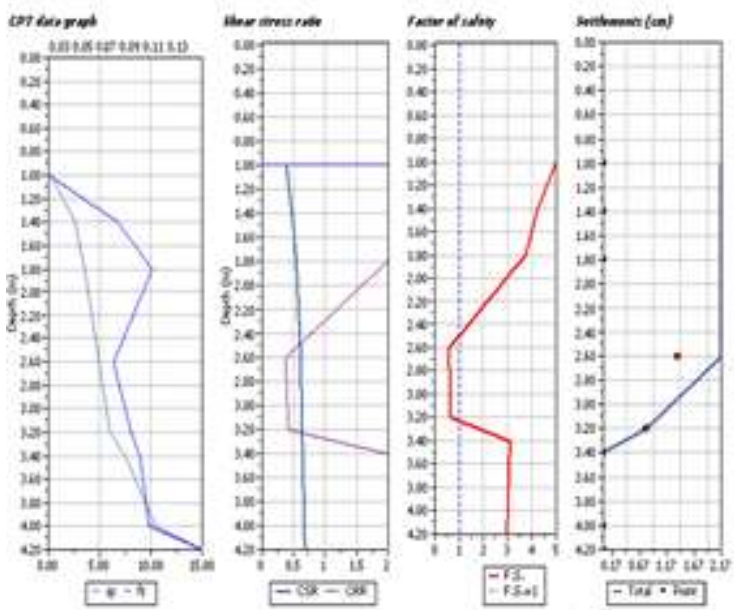

Gambar 4.4. Nilai faktor keamanan dan penurunan

Tabel 4.4.Penurunan dan faktor keamanan

\begin{tabular}{cc|c|c|l}
\hline $\begin{array}{l}\text { No } \\
\text { tik }\end{array}$ & Ti- & $\begin{array}{c}\text { Kedalaman } \\
(\mathrm{m})\end{array}$ & $\begin{array}{c}\text { Penurunan } \\
(\mathrm{cm})\end{array}$ & SF \\
\hline & 4 & 2,6 & 1,37 & 0.61 \\
& 5 & 3,2 & 0,80 & 0.65 \\
\hline \multicolumn{4}{|c}{ Total $=2,17 \mathrm{~cm}$} \\
\hline
\end{tabular}

Dari hasil analisa berdasarkan data sondir, titik yang mempunyai nilai faktor keamanan kurang dari 1 yaitu pada titik 4 dan 5 . Total penurunan yang terjadi yaitu sebesar 2,17 $\mathrm{cm}$.

\section{d. Siteba}

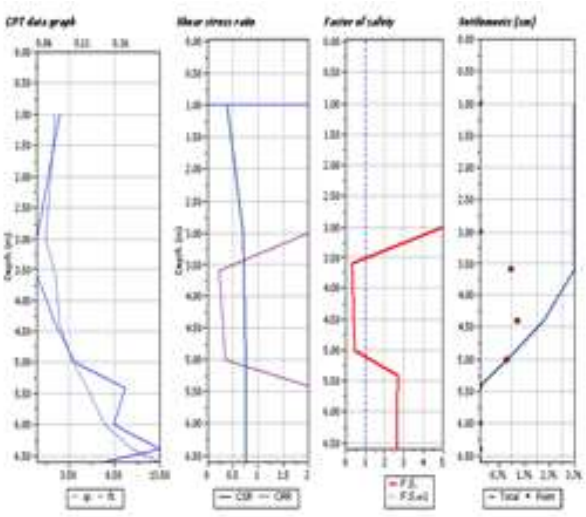

Gambar 4.5. Nilai faktor keamanan dan penurunan
Tabel 4.5.Penurunan dan faktor keamanan

\begin{tabular}{l|c|c|l}
\hline $\begin{array}{l}\text { No } \\
\text { Titik }\end{array}$ & $\begin{array}{l}\text { Kedalaman } \\
(\mathrm{m})\end{array}$ & $\begin{array}{c}\text { Penurunan } \\
(\mathrm{cm})\end{array}$ & SF \\
\hline 3 & 3,6 & 1,23 & 0.32 \\
4 & 4,4 & 1,47 & 0.41 \\
5 & 5,0 & 1,05 & 0.46 \\
\hline \multicolumn{3}{|c}{ Total $=3,76 \mathrm{~cm}$} \\
\hline
\end{tabular}

Dari hasil analisa berdasarkan data sondir, titik yang mempunyai faktor keamanan kurang dari 1 yaitu pada kedalaman $3,6 \mathrm{~m}, 4,4$ dan $5,0 \mathrm{~m}$. Total penurunan yang terjadi yaitu sebesar $3,76 \mathrm{~cm}$

e. Sungai Sapih
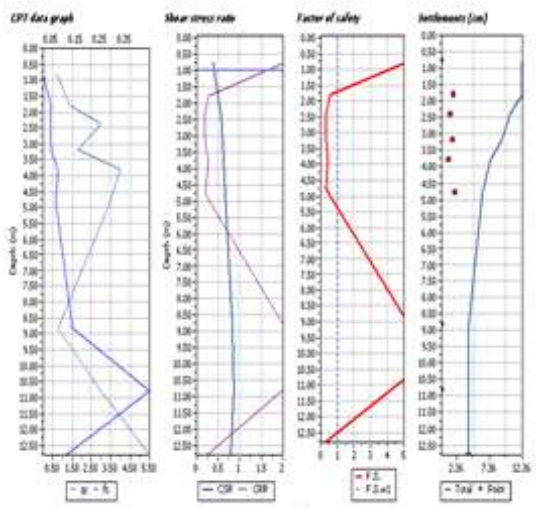

Gambar 4.6. Nilai faktor keamanan dan penurunan

Tabel 4.6.Penurunan dan faktor keamanan

\begin{tabular}{l|c|c|l}
\hline $\begin{array}{l}\text { No } \\
\text { Titik }\end{array}$ & $\begin{array}{l}\text { Kedalaman } \\
(\mathrm{m})\end{array}$ & $\begin{array}{c}\text { Penurunan } \\
(\mathrm{cm})\end{array}$ & SF \\
\hline 2 & 1,8 & 1,89 & 0.56 \\
3 & 2,4 & 1,34 & 0.34 \\
4 & 3,2 & 1,72 & 0.34 \\
5 & 3,8 & 1,16 & 0.42 \\
6 & 4,8 & 2,13 & 0.32 \\
9 & 12,8 & 4,12 & 0.29 \\
\hline \multicolumn{3}{|c|}{ Total = 12,36 cm } \\
\hline
\end{tabular}

Dari hasil analisa berdasarkan data sondir, titik yang mempunyai faktor keaman kurang dari 1 yaitu pada kedalaman 1,8 $\mathrm{m}$ sampai $12,8 \mathrm{~m}$. Total penurunan yang terjadi yaitu sebesar $12,36 \mathrm{~cm}$ 
f. Ujung Gurun
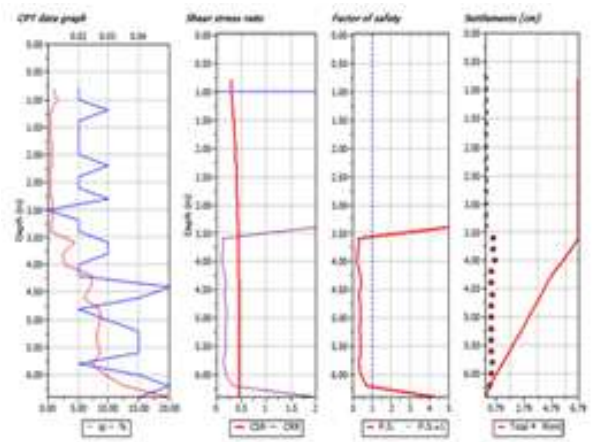

Gambar 4.7. Nilai faktor keamanan dan penurunan

Titik yang mempunyai faktor keaman kurang dari 1 yaitu pada kedalaman $3.5 \mathrm{~m}$ sampai 6.5 $\mathrm{m}$. Total penurunan yang terjadi yaitu sebesar $6.7 \mathrm{~cm}$.

\section{g. Lolong}
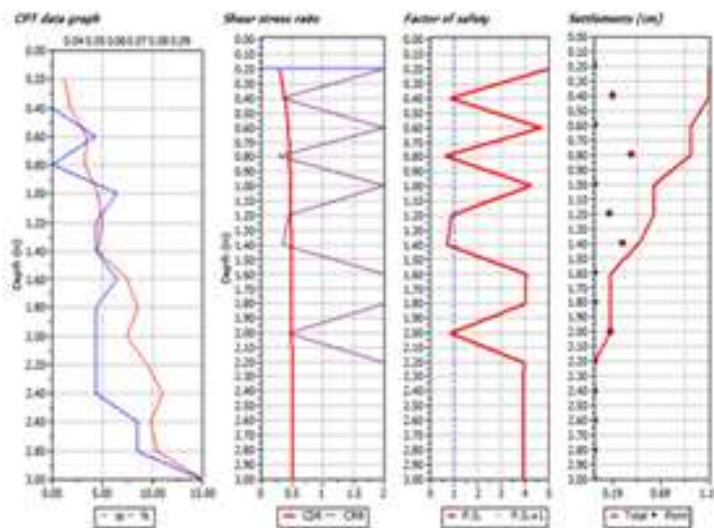

Gambar 4.8. Nilai faktor keamanan dan penurunan

Rata rata nilai faktor keamanan lebih besar dari 1 dan mendekati satu, hal ini menunjukkan bahwa pada lokasi tersebut tidak terjadi likuifaksi. i. Chatib Sulaiman

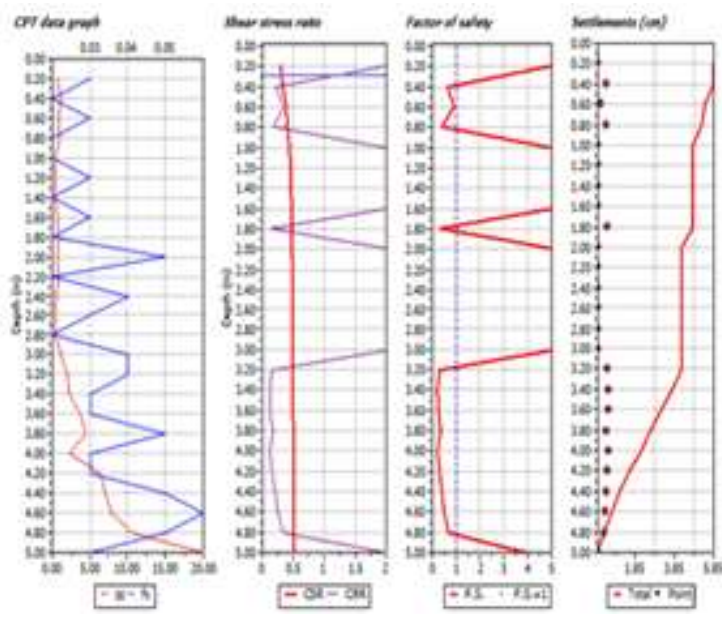

Dari hasil analisa berdasarkan data sondir, titik yang mempunyai faktor keaman kurang dari 1 yaitu pada kedalaman $3.2 \mathrm{~m}$ sampai 4.8 $\mathrm{m}$. Total penurunan yang terjadi yaitu sebesar $5.85 \mathrm{~cm}$.

Tabel 4.7. Rekapitulasi lokasi yang berpotensi likuifaksi

\begin{tabular}{|c|c|c|c|c|}
\hline No & Lokasi & $\begin{array}{c}\text { Kedalaman } \\
\text { (m) }\end{array}$ & $\begin{array}{l}\text { Liguefac } \\
\text { Hon } \\
\text { Potential }\end{array}$ & $\begin{array}{c}\text { Ketera } \\
\text { ngan }\end{array}$ \\
\hline 1 & $\begin{array}{l}\text { GOR Haji } \\
\text { Agussa } \\
\text { lim }\end{array}$ & $5 m-6 m$ & 32 & $\begin{array}{c}\text { Sangat Berpotensi } \\
\text { likuifaksi }\end{array}$ \\
\hline 2 & $\begin{array}{c}\text { Koto } \\
\text { Tangah }\end{array}$ & $3.8 \mathrm{~m}-2.2 \mathrm{~m}$ & 46,68 & $\begin{array}{c}\text { Sangat Berpotens } \\
\text { likuifaksi }\end{array}$ \\
\hline 3 & $\begin{array}{l}\text { Hoscokroa } \\
\text { minoto }\end{array}$ & $3.2 \mathrm{~m}-5 \mathrm{~m}$ & 5,180 & $\begin{array}{l}\text { Berpotensi } \\
\text { likuifaksi }\end{array}$ \\
\hline 4 & Purus & $2.6 \mathrm{~m}-3.2 \mathrm{~m}$ & 4,470 & $\begin{array}{l}\text { Tidak berpotensi } \\
\text { likuifaksi }\end{array}$ \\
\hline 5 & $\begin{array}{l}\text { Siteba } \\
\text { Padang }\end{array}$ & $3.6 m-5 m$ & 9,450 & $\begin{array}{l}\text { Berpotensi } \\
\text { likuifaksi }\end{array}$ \\
\hline 6 & $\begin{array}{l}\text { Sungai } \\
\text { Sapih }\end{array}$ & $1.8 \mathrm{~m}-12.8 \mathrm{~m}$ & 25,070 & $\begin{array}{c}\text { Sangat Berpotens } \\
\text { likuifaksi }\end{array}$ \\
\hline 7 & $\begin{array}{l}\text { Ujung } \\
\text { Gurun }\end{array}$ & $3.5 \mathrm{~m}-6.5 \mathrm{~m}$ & $>5$ & $\begin{array}{l}\text { Berpotensi } \\
\text { likuifaksi }\end{array}$ \\
\hline 8 & Lolong & $1 \mathrm{~m}-3 \mathrm{~m}$ & 1,000 & $\begin{array}{l}\text { Tidak berpotensi } \\
\text { likuifaksi }\end{array}$ \\
\hline 9 & $\begin{array}{l}\text { Chatib } \\
\text { Sulaiman }\end{array}$ & $3.2 \mathrm{~m}-4.8 \mathrm{~m}$ & $>5$ & $\begin{array}{l}\text { Berpotensi } \\
\text { likuifaksi }\end{array}$ \\
\hline
\end{tabular}

3.2 Titik Lokasi likuifaksi

Terdapat sembilan ( 9 ) titik penyelidikan di kota Padang ( gambar 4.9). 


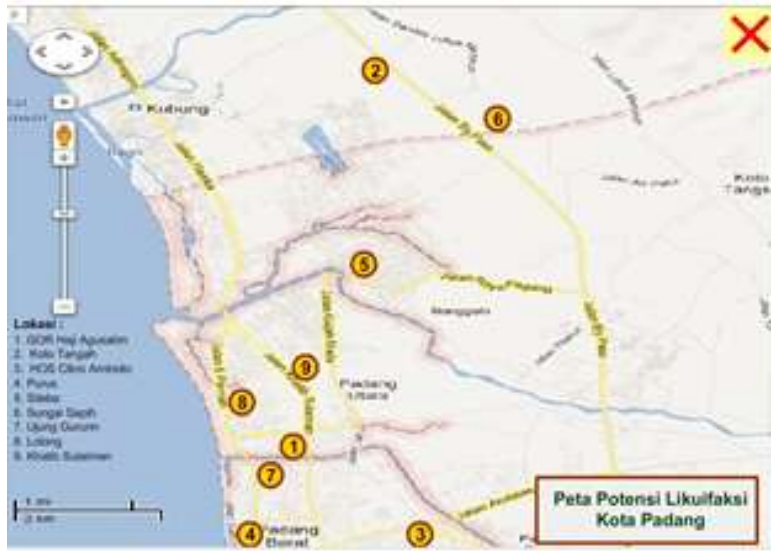

Gambar 4.9. Titik penyelidikan di kota Padang

Potensi likuifaksi pada masing masing lokasi (gambar 4.10)

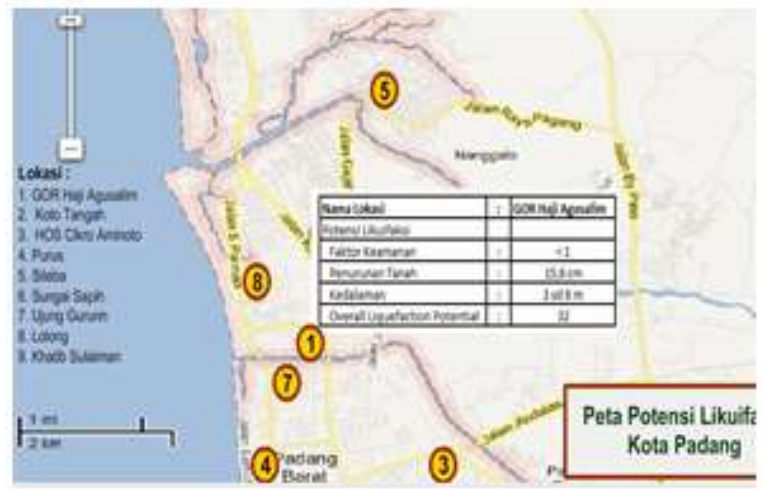

Gambar 4.10. Informasi potensi likuifaksi pada masing masing lokasi

\section{KESIMPULAN DAN SARAN}

\subsection{Kesimpulan}

1. Berdasarkan nilai faktor keamanan yang didapat untuk semua titik lokasi ( 9 titik lokasi), terdapat tujuh ( 7 ) lokasi yang mengalami likuifaksi dengan nilai faktor keamanan kurang dari 1, sedangkan untuk dua ( 2 ) lokasi yaitu Purus dan Lolong mempunyai nilai faktor keamanan mendekati 1 pada beberapa kedalaman tertentu.

2. Dari sembilan ( 9 ) titik lokasi yang ditinjau, berdasarkan tingkat liliquefaction Index umumnya terjadi likuifaksi, kecuali pada lokasi Purus dan Lolong kemungkinan sangat kecil terjadinya likuifaksi.

\section{Saran}

1. Data lapangan yang digunakan sebaiknya lebih banyak lagi pada satu lokasi, sehingga data yang diperoleh dapat mewakili kondisi lapangan.

2. Pengujian tanah dilaboratorium sangat diperlukan untuk mendapatkan sifat sifat fisis tanah disetiap kedalaman, sehingga menghasilkan analisa yang lebih akurat.

\section{DAFTAR PUSTAKA}

ASTM, 2003, Annual Book of ASTM Standards, section 4, volume 04.08 Soil and Rock.

Das.Braja M,1992, Principle os soil Dynamic PWS KENT Publishing Company

Hendarsin Shirley L 2003, Investigasi Rekayasa Geoteknik. Politeknik Negeri Bandung Jurusan teknik Sipil

Juang dan Chen (2001) mengusulkan persamaan empiris yang relatif baru untuk mengevaluasi tahanan tanah terhadap liquefaction

http://www.find-pdf.com/carigempa $\% 20$ dan $\%$ 20pencairan $\% 20$ tanah $\%$ 20pasir\% 20penelitian.html

Lai.SY, at all (2004) membuat model statistik untuk mengevaluasi potensi liguefaction dengan menggunakan data Cone Penetration test (Sondir).

http://www.find-pdf.com/cari-

gempa\%20dan\% 20pencairan\% 20tanah\% 20pasir\% 20penelitian.html

Ping-Sien Lin, at all, Characterization of Liquefaction Resistance in Gravelly Soil :

Large Hammer Penetration Test and Shear Wave Velocity Approach

http://www.find-pdf.com/carigempa\%20dan\% 20pencairan\% 20tanah\% 20pasir\% 20penelitian.html

Raharjo.P, 2000 Evaluasi Pencairan tanah pasiran saat gempa, short course, Pusat Pelatihan MBT bekerja sama dengan HATTI.

Tri Hatmoko.J, Lulie.Y 2008, Evaluasi Potensi pencairan tanah akibat gempa, Konferensi Nasional Teknik Sipil 2- Universitas Atma Jaya Yogyakarta Yogyakarta, 6 - 7 Juni 
2008, http://www.find- pdf.com /cariempa \%20dan \%20pencairan \%20tanah\% 20pasir\% 20penelitian.html

Soebowo.E, dkk, 2007 Studi Potensi Likuifaksi Di Daerah Zona Patahan Opak Patalan - Bantul, Jogjakarta Proseding Seminar Geoteknologi Kontribusi IImu Kebumian Dalam Pembangunan Berkelanjutan Bandung 3 Desember 2007.

Soebowo.E, dkk, 2009, Liquefaction Hazard Assesment of Opak fault zone in Sleman district, Jogjakarta,

http://www.geotek.lipi.go.id/riset/index.php/ jurnal/article/view/33

Ungkap M. Lumbanbatudan Suyatman Hidayat, 2007, Evaluasi awal kerentanan pelulukan/likuefaksi daerah Kendal dan sekitarnya, Jawa Tengah. Jurnal Geologi Indonesia, Vol. 2 No. 3 September 2007: 159-176 